\title{
Uji Stabilitas Spironolakton Terhadap Perubahan $p H$ dengan Menggunakan Kromatografi Cair Kinerja Tinggi (KCKT)
}

\section{Spironolactone Stability Test on pH Changes Using High Performance Liquid Chromatography (HPLC)}

\author{
Nelly Suryani ${ }^{1 *}$, Yardi, Supandi ${ }^{1}$, Ririn Astri Sabdowati ${ }^{1}$ \\ 1 Jurusan Farmasi, Fakultas Kedokteran dan IImu Kesehatan, Universitas Islam Negeri Syarif Hidayatullah Jakarta \\ Jakarta/Tangerang Selatan, Indonesia. \\ email: nelly.suryani@uinjkt.ac.id
}

\begin{abstract}
Abstrak
Spironolakton merupakan obat diuretic antagonis aldosterone untuk hipertensi. Pada prakteknya spironolakton terkadang digabungkan dengan obat-obat lain, dan pada pasien yang tidak sadarkan diri pemberian obat harus menggunakan feeding tube dan rentan akan ketidakstabilan.

Objek dari penelitian ini adalah untuk melihat pengaruh perubahan $\mathrm{pH}$ pada spironolakton tablet yang digerus dan disuspensikan di dalam air. Metode pengukuran kadar spironolakton menggunakan Kromatografi Cair Kinerja Tinggi berdasarkan metode dalam United State Pharmacopeia. Suspensi spironolakton dibuat dalam $\mathrm{pH} 3,5,7$, dan 9 dengan waktu pengambilan sampel pada menit ke $0,15,30,45$, dan 60 .

Hasil menunjukkan bahwa persen kadar spironolakton pada $\mathrm{pH} 3$ adalah $\leq 40 \%, p \mathrm{H} 5$ adalah $74 \%$ - 100\%. Pada $\mathrm{pH} 7$ berada dikisaran $27 \%-61 \%$, dan pada $\mathrm{pH} 9$ adalah $38 \%$ $54 \%$. Hal ini menjelaskan bahwa persen kadar spironolakton pada $\mathrm{pH} 3,7$, dan 9 pada semua waktu pengambilan sampel sudah tidak sesuai dengan kadar terapi minimum dalam monograph. Hanya pada $\mathrm{pH} 5$ kadar spironolakton masih sesuai dengan kadar yang ditentukan dalam monograph. Dalam penelitian ini dapat disimpulkan bahwa perubahan $\mathrm{pH}$ dapat menurunkan kadar spironolakton dalam suspensi secara signifikan.
\end{abstract}

Kata kunci : Stabilitas, Spironolakton, Suspensi, pH, KCKT

\begin{abstract}
Abstact
Spironolactone is an aldosterone diuretic antagonist for hypertension. In practice spironolactone is sometimes combined with other drugs, and in unconscious patients the drug must use a feeding tube and be susceptible to instability.

The object of this study was to see the effect of $p H$ changes on spironolactone tablets which were crushed and suspended in water. The method of measuring spironolactone levels using High Performance Liquid Chromatography based on methods in the United State

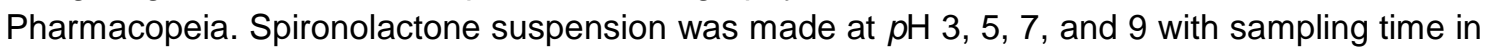
minutes $0,15,30,45$, and 60 .

The results showed that the level of spironolactone at $p \mathrm{H} 3$ was $\leq 0 \%, p \mathrm{H} 5$ was $74 \%$ $100 \%$, at $p \mathrm{H} 7$ it was in the range of $27 \%-61 \%$, and at $p \mathrm{H} 9$ was $38 \%-54 \%$. This explains that percent of spironolactone at $\mathrm{pH} 3.7$, and 9 at all sampling times did not match the minimum therapeutic level in the monograph. Only at $\mathrm{pH} 5$ does the level of spironolactone still match the levels specified in the monograph. In this study it can be concluded that changes in $\mathrm{pH}$ can significantly reduce spironolactone levels in suspension.
\end{abstract}

Keyword : Stability, Spironolactone, suspension, pH, HPLC 


\section{PENDAHULUAN}

Spironolakton merupakan obat diuretic antagonis aldosterone untuk hipertensi. Umumnya dibuat dalam bentuk tablet salut film tidak dalam bentuk larutan ataupun suspensi.(Mahmoud, banker) Spironolakton merupakan senyawa ester yang memiliki struktur lakton yang mudah terhidrolisis. Menurut studi oleh kaufman, senyawa yang mengandung struktur lakton mudah terhidrolisis. (Banker et al 2002, Min Li 2012, Niazi and Sarfaraz 2006).

Pada prakteknya spironolakton terkadang digabungkan dengan obatobat lain, dan pada pasien yang tidak sadarkan diri pemberian obat harus menggunakan feeding tube. Cara pemberian melalui feeding tube rentan akan ketidakstabilan. Ketidakstabilan dapat dideteksi melalui perubahan sifat fisika, kima, serta penampilan dari sediaan. (Niazi and Sarfaraz 2006, Ansel H.C 1994)

Bila bentuk sediaan obat diubah seperti diserbukkan, dilarutkan, ditambahkan dengan bahan lain atau dilakukan modifikasi faktor lingkungan kemungkinan dapat merubah stabilitas obat tersebut. Beberapa hal yang dapat mempengaruhi stabilitas dari sediaan adalah interaksi bahan aktif dengan bahan aktif lainnya. Faktor lingkungan seperti temperatur juga mempengaruhi stabilitas obat. (Lachman et al 2007, David et al 2006, The United States Pharmacopeial Convention 2007, Attwood dan Florence 2011).

Satu studi yang dilakukan oleh Nahata et al. mengemukakan bahwa suspensi spironolakton selama \pm 90 hari stabil dalam pendingin dan suhu kamar. Dekomposisi spironolakton terhadap $\mathrm{pH}$ menunjukkan bahwa nilai $\mathrm{pH}$ optimum spironolakton adalah $\mathrm{pH}$ 4.5 pada suhu $40^{\circ} \mathrm{C}$. Pada $\mathrm{pH}$ tersebut menunjukkan nilai dekomposisi minimum dengan nilai $\mathrm{K}: 0.00095$ [9, 10]. Tujuan dari studi ini adalah untuk menganalisa kadar suspensi spironolakton dalam variasi $\mathrm{pH}$.

\section{Material}

Material yang digunakan dalam studi ini adalah zat aktif standar dari sigmaaldrich, tablet spironolakton (Letonal) $25 \mathrm{mg}$, aquabidest dari Wida dan metanol HPLC grade dari Merck. Untuk pengujian $\mathrm{pH}$ larutan dapar yang dibuat dari $\mathrm{KH}_{2} \mathrm{PO}_{4}$ dan $\mathrm{K}_{2} \mathrm{HPO}_{4}$.

\section{Instrument}

Alat yang digunakan dalam pengujian ini adalah KCKT (Dionex Ultimate 3000) dengan software chromaleon sebagai intrumen utama. Selain itu juga menggunakan spectrophotometer (hitachi u-2910) untuk menentukan panjang gelombang.

\section{METODE PENELITIAN}

\section{Penentuan panjang gelombang maksimum}

Larutan standar spironolakton dibuat dengan cara melarutkan zat standard hingga didapat konsentrasi 10 ppm yang kemudian diuji menggunakan spectrophotometer untuk mendapatkan panjang gelombang maksimum.

\section{Uji kesesuaian sistem}

Larutan standar spironolakton dibuat dalam konsentrasi 100 ppm, kemudian diinjeksikan ke instrument KCKT sebanyak $10 \mu \mathrm{L}$ dengan menggunakan fase gerak metanol : aquabidest $60: 40$ ( $\mathrm{v} / \mathrm{v})$ dengan column C18 $(5 \mu \mathrm{m}$ $4,6 \times 250 \mathrm{~mm}$ ), diulang sebanyak 6 kali (Attwood D dan Florence 2011). Kemudian dilihat nilai dari theoretical 
plates, RSD (Relative Standard Deviation), peak area, retention time dan tailing factor. Sistem ini dilakukan untuk memverifikasi dan menguji stabilitas instrument.

\section{Pengujian verifikasi instrument}

\section{Akurasi dan Presisi}

Pengujian menggunakan larutan standar spironolakton dengan konsentrasi 80, 100 dan 120 ppm. Larutan standar masing masing diinjeksikan dan diuji dengan sistem yang sesuai. Pada tes akurasi, larutan standar masing masing diinjeksikan sebanyak 3 kali dan kemudian dihitung nilai persentase recovery dan persentase differensiasi. Pada uji presisi, larutan standar diinjeksikan sebanyak 3 kali dan dihitung nilai SD dan RSD. Pada pengujian antar waktu proses injeksi dilakukan pada jam ke 0 dan ke 6 , dan pada pengujian intra hari dilakukan pada hari pertama dan hari kedua dan kemudian dihitung nilai SD dan RSD (Harmita. 2004).

\section{Determinasi kurva kalibrasi}

Larutan standar spironolakton dibuat menjadi seri 25, 50, 75, 100, 125, and 150 ppm. Kemudian diinjeksikan dan diuji menggunakan sistem yang sesuai. Kemudian akan didapatkan nilai absobansi dan dibuat dalam bentuk kurva yang linear. Serta dihitung nilai LOD dan LOQ (Harmita. 2004).

\section{Pengujian Stabilitas}

Suspensi sederhana spironolakton dalam air yang diuji dalam perbedaan nilai $\mathrm{pH}$ dalam rentang waktu yang berbeda. Waktu yang ditentukan dalam pengujian sampel adalah $0,15,30,45$ dan 60 menit dengan nilai $\mathrm{pH} 3,5,7$ dan 9.

Suspensi dibuat dengan cara menggerus tablet dan dilarutkan atau disuspensikan dengan air. Sampel didiamkan selama rentang waktu pengujian, dan disonifikasi setiap 1 menit sebelum waktu pengambilan cuplikan. Setelah cuplikan diambil kemudian diencerkan menjadi 100 ppm dengan metanol dan di adjust dengan dapar fosfat untuk menyamakan $\mathrm{pH}$ sampel dengan $\mathrm{pH}$ optimum spironolakton yaitu $\mathrm{pH} \quad 4.5$ dan kemudian di vortex selama 5 menit. Lalu disentrifugasi selama 5 menit dengan kecepatan 5000 rpm dengan temperatur $25^{\circ} \mathrm{C}$. Supernatan kemudian diambil dan disaring menggunakan syringe filter 0.45 dan dimasukan kedalam vial untuk diuji dengan menggunakan KCKT. Kemudian luas area peak yang muncul dihitung dengan menggunakan persamaan regresi linear dari kurva kalibrasi (Suryani et al 2013).

\section{HASIL DAN PEMBAHASAN \\ Uji Kesetaraan Sistem}

Hasil pengujian menunjukkan nilai efisiensi kolom dan nilai RSD of peak area, dan waktu retensi RSD yang sesuai dan didapatkan hasil sistem yang sesuai sebagai berikut: spironolakton yang diinjeksikan ke KCKT sebanyak $100 \mu \mathrm{L}$ dengan fase gerak methanol : aquabidest $60: 40$ (v / v) menggunakan column $\mathrm{C} 18(5 \mu \mathrm{m}$ $4,6 \times 250 \mathrm{~mm}$ ).

\section{Uji Verifikasi Akurasi dan Presisi}

Hasil pengujjian menunjukan nilai recovery dalam rentang $94-104 \%$, sesuai dengan nilai batas yang ditentukan yaitu pada rentang 90$107 \%$. Hasil pengujian juga menunjukan nilai RSD tiap konsentrasi adalah $\leq 2 \%$, sesuai dengan ketentuan. 




Fig. 1 Chromatogram dari Spironolactone, 1) Larutan standar; 2) spironolakton tablet yang disuspensikan

\section{Kurva Kalibrasi}

Hasil pengujian menunjukan nilai dari $r$ $=0.9998, \mathrm{y}=1.7856 \mathrm{x}+2.5175$, nilai koefisien determinasi $=99.939 \%$, Theoritical plates (USP) $=2560$, dan Peak Asymetry $=0.871$.

\section{Uji Stabilitas}

Berdasarkan literatur USP 30, persen kandungan kadar spironolakton yang sesuai adalah tidak kurang dari 95\% dan tidak lebih dari 105\%.

Berdasarkan grafik perbandingan $\mathrm{pH}$ terhadap waktu (Gambar 2), pada $\mathrm{pH} 3,7$, dan 9 terjadi penurunan kadar secara drastis dari kadar sejak awal pengujian yaitu $>60 \%$ dari kadar awal. Sedangkan pada $\mathrm{pH} 5$ penurunan kadar saat awal pengujian tidak terjadi secara drastis.

Tabel. 1 Konsentrasi (\%) Spironolakton

\begin{tabular}{ccccc}
\hline Waktu (menit) & \multicolumn{4}{c}{ Konsentrasi (\%) } \\
& $\mathrm{pH} \mathrm{3}$ & $\mathrm{pH} \mathrm{5}$ & $\mathrm{pH} \mathrm{7}$ & $\mathrm{pH} \mathrm{9}$ \\
\hline 0 & 19 & 100 & 61 & 54 \\
\hline 15 & 21 & 88 & 46 & 50 \\
\hline 30 & 22 & 85 & 38 & 41 \\
\hline 45 & 27 & 74 & 27 & 38 \\
\hline 60 & 40 & 91 & 35 & 38 \\
\hline
\end{tabular}




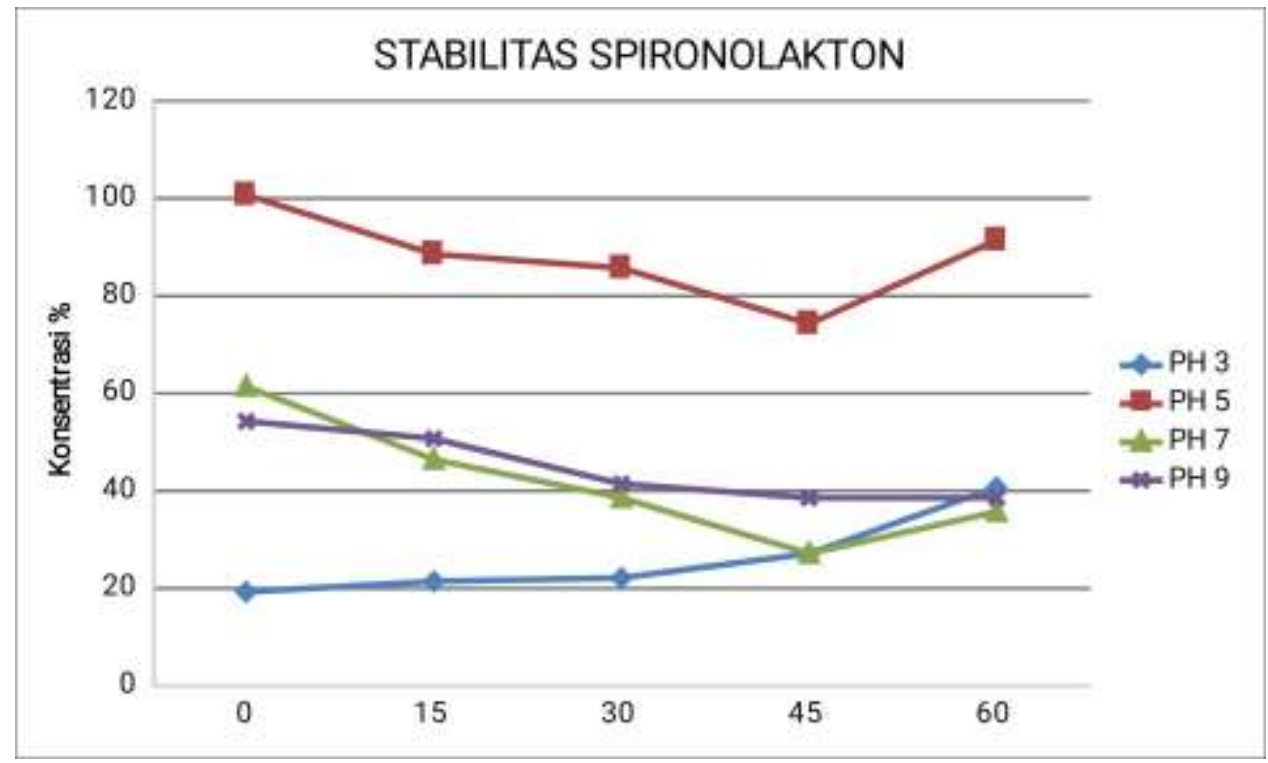

Gambar 2. Kurva degradasi spironolakton

Berdasarkan grafik gambar 2 juga dapat terlihat bahwa pada menit ke-60 terjadi kenaikan kadar. Kenaikan ini kemungkinan besar di sebabkan oleh terjadinya reaksi hidrolisis pada struktur spironolakton. Setelah spironolakton mengalami hidrolisis, kemungkinan terbentuk senyawa baru yang mirip dengan spironolakton. Hail inilah yang mungkin menyebabkan terjadinya perubahan luas peak area. Senyawa yang terbentuk dari hasil hidrolisis ini mungkin terbaca pada waktu retensi yang hampir sama atau sama dengan spironolakton (Jankowski et al 1996).

Oleh karena itu, perlu dilakukan studi lanjutan dengan menggunakan metode analisa dengan menggunakan metode gradient untuk dapat memisahkan hasil degradasi dari spironolakton dan mengetahui apa hasil degradasi dari spironolakton tersebut.

\section{KESIMPULAN}

Berdasarkan hasil penelitian kadar spironolakton pada semua $\mathrm{pH}$ tidak memenuhi pesyaratan sesuai ketentuan kadar spironolakton dalam sediaan.

\section{DAFTAR PUSTAKA}

Banker, Gilbert $S$ and $C$ T Rhodes, 2002, Modern Pharmaceutics: Fourth Edition, Revised, and Expanded, Marcel Dekker, Inc, New York

Min Li, 2012, Organic Chemistry of Drug Degradation, The Royal Society of Chemistry, Cambridge

Niazi, Sarfaraz, 2006, Handbook of Preformulation: Chemical, Biological, and Botanical Drugs, Informa Healthcare USA Inc, New York

Ansel H.C, 1994., Pengantar Bentuk Sediaan Farmasi, ed 4, Penerjemah Farida Ibrahim, Universitas Indonesia Press, Jakarta, 155-164

Lachman, L., Lieberman, H. A., Kanig, J. L., 2007, Teori dan Praktek Farmasi Industri, Edisi ketiga, 
diterjemahkan oleh: Suyatmi, S., Penerbit Universitas Indonesia, Jakarta, 760-779, 1514 - 1587

David B. Troy,Paul Beringer, 2006, Remington's Pharmaceutical Sciences, 21th ed, Lippincott Williams \& Wilkins,

The United States Pharmacopeial Convention. 2007. The United States Pharmacopeia $30^{\text {th }}$ Edition- National Formulary $25^{\text {th }}$ Edition. USA

Attwood D dam Florence, 2011, Physicochemical Principles of Pharmacy Ed.5, Chapman and Hall Inc

Pramar, Yasoda and V, D. Gupta, 1990, Preformulation Studies of Spironolactone : Effect of $\mathrm{pH}$, Two Buffer Species, Ionic Strength, and Temperature on Stability, Departemen of Pharmaceutics, University of Houston, TX 77030

BasuSarkar,A, Kandimalla A, Dudley R ,2013, Chemical Stability of Compounded Spironolactone Suspension in Proprietary Oral Mix Over a 90-day Period at Two Controlled Temperatures in Different Storage Containers, Int. J. Pharm. Sci. Rev. Res., 23(1), Nov-Dec 2013, ISSN 0976044X

International Conference on Harmonisation/ICH. 2005. Validation of Analytical Procedures: Text and Methodology Q2(R1). ICH Harmonised Tripartite Guideline. 2(1): 6.

Harmita. 2004. Petunjuk Pelaksanaan Validasi Metode dan Cara
Perhitungannya. Majalah IImu Kefarmasian, Vol.I, No.3, 117135. ISSN: 1693-9883

Suryani, $N$, Sato $H$, Sugiyama $E$, Kurata N, 2013. Stability of Ester Prodrugs with Magnesium Oxide Using The Simple Suspenssion Method. Jpn. J. Pharm Health Care Sci. 39 (6) 375-380

Jankowski $\quad A^{1}$, Skorek-Jankowska A, Lamparczyk $\mathrm{H}$. Simultaneous determination of spironolactone and its metabolites in human plasma, J Pharm Biomed Anal. 1996 Jun;14(8-10):1359-65 